Nevșehir Bilim ve Teknoloji Dergisi TARGíd Özel Sayı 332-344 2016

DOI: 10.17100/nevbiltek.211029

URL: http://dx.doi.org/10.17100/nevbiltek.211029

\title{
Ekzopolisakkaritlerin Özellikleri ve Gıda Sanayindeki Önemi
}

\author{
Ali Soyuçok ${ }^{1}$, Teslime Ekiz², Gülden Başyiğit Kılıç ${ }^{1 *}$ \\ ${ }^{1}$ Mehmet Akif Ersoy Üniversitesi, Mühendislik-Mimarlkk Fakültesi, Glda Mühendisliği Bölümü, Burdur \\ ${ }^{2}$ Afyon Kocatepe Üniversitesi, Mühendislik Fakültesi, Glda Mühendisliği Bölümü, Afyonkarahisar \\ Öz
}

Ekzopolisakkarit (EPS)'ler mikroorganizmalar tarafindan hücre dışına sentezlenen polisakkaritler olup, hücre duvarına bağlanan EPS'ler kapsüler ekzopolisakkarit, ortamda serbest halde bulunanlar ise mukoz ekzopolisakkarit olarak sınıflandırılmaktadır. Son yıllarda EPS üretme yeteneğine sahip mikroorganizmaların kullanımı giderek yaygınlaşmaktadır. EPS'ler sindirim sisteminden sindirilmeden geçtiği için prebiyotik özellik göstermektedir. Ayrıca EPS'nin sağlık üzerine olumlu etkileri de bulunmaktadır. Yapılan çalışmalarda EPS'lerin bağışıklık sistemini geliştirici, kolesterolü düşürücü, antiülser ve antitümör etkisinin olduğu belirtilmiştir. EPS'ler gıda endüstrisinde jelleştirici, emülsifiye ve stabilize edici özelliklerinden dolayı kullanılmaktadır. EPS'ler fermente ürünlerin stabilitesini, teknolojik ve tekstürel yapısını geliştirirken, bakterileri faj saldırılarına, toksik bileşiklere, ozmotik strese ve kurumaya karşı korumaktadır. Özellikle yoğurtta meydana gelen gevşek yapı ve serum ayrılması gibi yapı bozukluklarının doğal yollarla giderilmesi için EPS üreten laktik asit bakterilerinin kullanımı tercih edilmektedir. Bu bakteriler ürünün viskozitesi ve su tutma kapasitesini geliştirerek son ürünün fonksiyonel özelliklerini ve kalitesini arttırmaktadır. Bu çalışmada, ekzopolisakkaritlerin gıda endüstrisindeki önemi belirtilmiş; gıda kalitesi üzerine yapılan çalışmalardan örnekler sunulmuştur.

Anahtar Kelimeler: Ekzopolisakkarit, laktik asit bakterileri, gıda sanayi

\section{The properties of Exopolysaccharides and Their Importance in Food Industry}

\begin{abstract}
Exopolisaccharides (EPS) are polysaccharides which synthesized out of the cell by microorganisms. Synthesized exopolysaccharides (EPS), either capsular polysaccharides (CPS) that are tightly associated with the cell surface or slime EPS that are secreted into the extracellular environment. In recent years, uses of microorganisms which have ability to produce EPS are becoming increasingly common. EPSs are described as prebiotic because of non-digestible. Besides EPSs have positive effects on human health. EPS are reported to function as to improve immune stimulation, cholesterol lowering capability, antiulcer and antitumor activities. Moreover, EPSs are commonly used food industry due to properties of thickeners, emulsifiers and stabilizers. EPSs improves the stability, technological and textural structure of fermented products furthermore EPSs preserve bacteria against phage attacks, toxic compounds, osmotic stress and dryness. EPS producer lactic acid bacteria are usually preferred to decrease syneresis in yoghurt and improve the stability of dairy products thus these problems are resolved in a natural way. These bacteria improve binding water and viscosity of product thus functionality and quality of final product are improved. In this study, the importance of exopolysaccharides in the food industry and studies on improving the quality of food with using EPS are presented.
\end{abstract}

Keywords: Exopolysaccharide, lactic acid bacteria, food industry

\footnotetext{
*e-mail: gkilic@mehmetakif.edu.tr
} 


\section{Giriş}

Polisakkaritler gıdalarda stabilizatör, emülgatör, jelleştirici veya su bağlayıcı ajan olarak kullanılmaktadır. Nişasta, galaktomannan, pektin, karreganan ve aljinat gibi bitki ve yosunlardan elde edilen polisakkaritler gıda sanayisinde kullanılan polisakkaritlerin büyük çoğunluğunu oluşturmaktadır [1]. Son yıllarda bitki ve yosunlardan üretilen polisakkaritlere alternatif olarak çok düşük konsantrasyonda bile viskoz çözelti oluşturmaları ve pseudoplastik yapıya sahip olmaları nedeniyle mikrobiyal ekzopolisakkaritlerin kullanımına olan ilgi artmaktadır [2].

Ekzopolisakkarit (EPS)'ler mikroorganizmaların bulundukları ortama salgıladıkları monosakkaritlerin yüksek molekül ağırlığına sahip, geri dönüşebilen ve çevre dostu doğal polimerleridir. Mikroorganizmaların sentezledikleri EPS'ler hücre içi, hücre duvarı ve hücre dışı olmak üzere farklı spektrumlar gösterebilmektedir. Mikrobiyal polisakkaritler; hücre için karbon ve enerji depolamada görevli olan intraselüler polisakkaritler, hücre duvarının ayrılmaz bileşeni olarak etki gösteren, lipopolisakkarit ve teoik asit gibi hücre yapılarının bileşeni olan yapısal polisakkaritler ve EPS'ler olarak adlandırılan ekstraselüler polisakkaritler olmak üzere üç gruba ayrılır [3]. EPS’ler arke, bakteri ve ökaryotların farklı türleri tarafından üretilmektedir [4].

Mikrobiyal EPS’lerin yosun ve bitki kaynaklı EPS’lere karşı üstün özellikleri vardır [5]. Son on yılda ekstremofillerden sentezlenen EPS'ler rapor edilmiştir. Bu EPS'lerin kompozisyon, yapı, sentezlenme özellikleri ve fonksiyonel özellikleri farklılıklar göstermektedir. Yoğun olarak araştırılmakta olan bu konuların henüz az bir kısmı sanayiye taşınabilmektedir. Çoğunlukla termofil ve halofil olan arkea cinslerinde EPS üretimi rapor edilmiştir. Arkea ve bakterilerin termofil cinsleri sicak bölgeler ve kaplıcaların yüzeyi ve dipleri gibi termal ekosistemlerden izole edilebildiği için bu yerler mikrobiyal EPS üreticileri için önemli kaynaklardır. Termofil arkea türleri arasında Thermococcus ve Sulfolobus'in EPS sentezlediği belirtilmiştir [6, 7].

EPS'lerin tekstil, petrol arıtma, madencilikte metal ayırma, endüstriyel atık arıtma, ilaç üretme, kozmetik, tıp ve gıda sanayisi gibi geniş bir yelpazede bir çok kullanım potansiyeli vardır [1]. EPS’lerin gıda sanayinde kıvam artırııı, jelleştirici ve emülsifiye edici özellikleri sebebiyle kullanılmaktadır [5]. Bu derlemede EPS'nin özelliklerinden bahsedilmiş, gıda sanayindeki önemi hakkında bilgiler verilmiş ve gıda kalitesi üzerine yapılmış çalışmalardan örnekler sunulmuştur.

\section{EPS'nin Genel Özellikleri}

EPS’ler, D-glikoz, D-galaktoz, L-ramnoz veya nadir olarak N-asetilglikozamin, Nasetilgalaktozamin ve glukoronik asit içeren birimlerin tekrarlanması sonucu açığa çıkan yapılardır [8]. Mikrobiyal EPS'ler doğada iyonik veya iyonik olmayan formda bulunabilir ve suda çözünebilir [9]. Molekül büyüklükleri genel olarak $10 \mathrm{kDA}$ ile $200 \mathrm{kDa}$ arasında değişmekte bazen de $1000 \mathrm{kDa}$ 'ya çıkabilmektedir [10]. EPS’ler mikroorganizmayı kurumaya, fagositoza, faj saldırılarına, antibiyotiklere, toksik bileşiklere ve ozmotik strese karşı korurlar [11]. Ayrıca biyofilm oluşumu ve hücrenin katı yüzeylere tutunmasında etkili olup [12], antimikrobiyal maddelerin difüzyonunu sınırlandırırlar [13].

EPS'ler mikroorganizmaların çevresini saran polimer yapılardır. Hücre dışında bulunan karbonhidratlar, proteinler, peptitler EPS'lerin ortamdan zor ayrılmasina neden olur [14]. EPS üreten mikroorganizmaların geliştiği ortam ve optimum şartlar EPS'nin kalitesini ve verimini etkilemektedir. Bu 
etmenlerin arasında karbon ve azot kaynakları, ortamda bulunan moleküller, mineral tuzlar, iz elementler, mikroorganizma cinsi, sicaklık, pH ve oksijen konsantrasyonu önemlidir [15].

EPS’ler iki gruba ayrılırlar. Bunlardan birincisi tek tip monosakkaritten meydana gelen homopolisakkaritler (HoPS), diğeri ise oligosakkaritlerin çoklu kopyalarından oluşan ve her bir tekrarlı birimde iki ya da daha farklı monosakkarit içeren heteropolisakkaritler (HePS)'dir [16]. HoPS'ler; $\alpha$-Dglukanlar, $\beta$-D-glukanlar, fruktanlar ve poligalaktanlar olmak üzere dört gruba ayrılmaktadırlar. Bunlardan $\alpha$-D-glukanlar, genellikle Leuconostoc mesenteroides subsp. mesenteroides, Leu. mesenteroides subsp. dextranicum, Streptococcus mutans ve Str. sobrinus, $\beta$-D-glukanlar Pediococcus spp. ve Streptococcus spp., fruktanlar Str. salivarius tarafından üretilmektedir [12]. HePS ise genellikle Lactoccous lactis, Lactobacillus sakei, L. rhamnosus ve L. casei gibi mezofil laktik asit bakterileri (LAB) ve L. acidophilus, L. delbrueckii subsp. bulgaricus (L. bulgaricus), L. helveticus ve Str. salivarus subsp thermophilus (Str. thermophilus) gibi termofil LAB tarafindan üretilmektedirler [10]. Ksantan gam, gellan gam, aljinat, glukanlar, hiyalüronik asit, süksinoglukan ve levan, üzerinde yoğun çalışmalar yapılan ve ticari olarak kullanılan bakteriyel ekzopolisakkaritlerdir [2].

Avrupa Birliği (AB) ülkelerinin çoğunda stabilizatör kullanımının yasak olmasından dolayı kıvam artırıcı kültür kullanımı oldukça yaygındır. Süt endüstrisinde kıvam artırıcı LAB içeren başlatıcı kültürler AB ülkeleri ve Amerika'da ticari kültür olarak piyasada satılmaktadır. Farklı LAB'tan üretilen EPS’ler; kimyasal kompozisyon, elektriksel yük, üç boyutlu yapı, pıhtı sağlamlı̆̆ı, proteinlerle interaksiyon yapabilme yetenekleri gibi birçok özellik bakımından değişkenlik gösterir [8]. Düşük yağ ve şeker içeriğine sahip, inorganik gıda katkı maddesi içermeyen gıdalara olan tüketici talepleri, üreticilerin EPS içeriği yüksek gıdalara yönelmesine sebep olmuştur.

\section{EPS Üretimini Etkileyen Etmenler}

EPS üretimi bakteriyel üreme ile yakından ilgilidir. Optimum koşullar altında EPS üretim miktarı yüksek seviyeye ulaşmaktadır. Bakteriyel gelişim ve EPS üretimi; besiyerine karbonhidrat, azot kaynağı, vitamin, tuz gibi maddelerin ilavesi, ayrıca inkübasyon sıcaklığı ve süresi, oksijen seviyesi, $\mathrm{pH}$ gibi etmenlerden etkilenmektedir [12, 17]. EPS üretimi için en çok kullanılan karbon kaynakları glikoz ve sakarozdur. Sakaroz EPS üretiminde en uygun karbon kaynağı olarak sıklıkla kullanılmaktadır [18, 19]. Son yıllarda yapılan çalışmalarda sakarozun karbon kaynağı olarak kullanılmasının levan tipi EPS verimini artırdığ 1 rapor edilmiştir [20].

Bakteriyel EPS üretimi genellikle aerobik koşullar altında gerçekleşmektedir. Ksantam gum gibi bazı EPS'ler için maksimum havalandırma gerekirken, bakteriyel aljinat için mikroaerofilik koşullar gerekmektedir [21]. Sıcaklığın LAB tarafından üretilen EPS’ler üzerine etkisinin incelendiği bir çalışmada Mozzi ve arkadaşları [22] L. acidophilus'un $37{ }^{\circ} \mathrm{C}$ ve $42{ }^{\circ} \mathrm{C}$ 'de 24 saatlik inkübasyonu sonucunda EPS üretiminin yüksek, $30{ }^{\circ} \mathrm{C}$ 'de ise çok daha düşük olduğu tespit edilmiştir. EPS üretim yeteneğine sahip L. rhamnosus JAAS8 suşunun, EPS üretim yeteneğine sahip olmayan yoğurt suşlarının kombinasyonu ve diğer EPS üretmeyen başlatıcı kültürlerle karşılaştırıldığında fermente süt ürünlerinin su tutma kapasitesi ve viskozitesini artırdığı belirtilmiştir [23]. Fermente süt ürünlerinde EPS üretmeyen L. bulgaricus'un EPS üretimine sahip L. rhamnosus JAAS8 ile kısmen veya tamamen yer değiştirmesi sonucunda viskozite sırasıyla \%16 ve \%21 artmış, su tutma kapasitesi ise \%2 artış göstermiştir [24]. 
Yapılan farklı çalışmalarda yüksek EPS üretim özelliğine sahip Leuconostoc spp. 208 [17], Leuc. mesenteroides subps. pseudomesenteroides 406 ve Leuc. citreum 52 [25] suşları kullanılarak farklı büyüme koşullarında EPS üretimi incelenmiştir. Çalışmada $20^{\circ} \mathrm{C}, 28^{\circ} \mathrm{C}, 37^{\circ} \mathrm{C}$ ve $42{ }^{\circ} \mathrm{C}$ olmak üzere dört farklı sıcaklık test edilmiştir. Leuc. citreum 52 ve Leuconostoc subps. 208 suşları en fazla canlı hücreye $20^{\circ} \mathrm{C}$ 'de 24 saat inkübasyon sonrası ulaşırken, Leuc. mesenteroides subps. pseudomesenteroides 406 suşu $28{ }^{\circ} \mathrm{C}$ 'de 24 saat inkübasyon sonrası ulaşmıştır. Leuc. mesenteroides subps. pseudomesenteroides 406 suşu $37{ }^{\circ} \mathrm{C}$ ve $42{ }^{\circ} \mathrm{C}$ ' de 48 saat inkübasyon sonrası ise zayıf gelişme göstermiştir.

Stres koşulları altında mikrobiyal hücreleri korumak amacıyla EPS üretimi artmaktadır [26]. Grosu-Tudor ve Zamfir [17] tarafından yapılan bir çalışmada üreme ortamına stres faktörü olarak çeşitli konsantrasyonlarda $\mathrm{NaCl}$ ilave edilmiştir. İncelenen tüm suşlar $28^{\circ} \mathrm{C}$ 'de $\mathrm{NaCl}$ varllğında iyi gelişme göstermiş̧tir. Leuc. mesenteroides subps. pseudomesenteroides 406 suşunun $\% 5 \mathrm{NaCl}$ varlığında $28{ }^{\circ} \mathrm{C}$ 'de 24 saatlik inkübasyon sonrası, optimum koşullara göre daha fazla EPS ürettiği ancak biyokütle üretiminin en az seviyede olduğu belirtilmiştir. Fakat Leuc. citreum 52 suşunun $\% 1 \mathrm{NaCl}$ konsantrasyonunda 1.68 g/L EPS ürettiği tespit edilmiştir.

Sütte farklı mikroorganizmalar tarafindan üretilen EPS miktarı farklılık göstermektedir. EPS miktarını Str. thermophilus için 50-350 mg/L [27, 28], L. bulgaricus için 60-150 mg/L [29] ve Lc. lactis subp. cremoris için ise $80-600 \mathrm{mg} / \mathrm{L}$ aralığında [30] olduğu belirtilmiştir. Patel ve arkadaşları [31], L. fermentum'un ürettiği EPS miktarının $250 \mathrm{mg} / \mathrm{L}$, L. plantarum tarafindan üretilen EPS'nin ise 390-960 $\mathrm{mg} / \mathrm{L}$ olduğunu rapor etmişlerdir. Normal şartlarda 50-60 mg/L EPS üreten $L$. casei besiyerinin optimizasyonu sırasında ortama glikoz ve sukroz ilave edilmesiyle EPS miktarı yaklaşık $200 \mathrm{mg} / \mathrm{L}$ ulaşmıştır [14].

Van Geel-Schutten ve arkadaşları [32] tarafindan yapılan çalışmada EPS üretimleri incelenen 182 adet Lactobacillus suşundan 60 tanesinin EPS ürettiği, bunlardan 17 suşun EPS üretiminin 100 mg/L'den fazla olduğu belirtilirken, EPS üretimi için en uygun bileşenin sakaroz olduğu kaydedilmiştir. Benzer şekilde Str. thermophilus Rs ve St suşları tarafindan $135 \mathrm{mg} / \mathrm{L}$ ve $127 \mathrm{mg} / \mathrm{L}$ EPS üretildiği belirtmiştir [33]. Yapılan diğer araştırmalarda LAB tarafından üretilen EPS'lerin miktarlarının 150-600 $\mathrm{mg} / \mathrm{L}$ arasında olduğu rapor edilmiştir [8, 12].

Shihata ve Shah [34] proteolitik özellikteki L. bulgaricus'un ticari ABT başlatıcı kültürler ( $L$. acidophilus, Bifidobacterium subsp. (BB-1, BB-4 ve BB-20210) ve Str. thermophilus) ile birlikte kullanıldığında yoğurt özellikleri üzerine etkilerini incelemiş ve bu kültürlerin farklı kombinasyonlar şeklinde kullanılması ile yoğurt örneklerindeki EPS miktarının 2.76-3.64 g/100g arasında değiştiğini tespit etmiştir. Lin ve Chang Chien [35] tarafından yapılan araştırmada 32 ile 84 saat arasında değişen fermantasyon süresinde $L$. helveticus BCRC14030 ve BCRC14076 ve Str. thermophilus BCRC 14085'in sırasıyla $0.25-0.73,0.63-0.93,0.73-0.93 \mathrm{mg} / \mathrm{mL}$ EPS ürettiğgi tespit edilmiştir. Farklı besiyeri bileşenlerinin B. longum subsp. infantis CCUG 52486 ve B. infantis NCIMB 702205'in EPS üretimi üzerine etkisinin incelendiği çalışmada \%1.5 kazein hidrolizat varlığında suşların sırasıyla 0.285 ve 0.102 $\mathrm{mg} / \mathrm{mL}$ EPS ürettikleri belirlenmiştir [36]. Str. thermophilus suşları ile üretilen yoğurtlardan ST 1275 suşu ile $42{ }^{\circ} \mathrm{C}$ 'de inkübe edilen yoğurtta $860 \mathrm{~g} / \mathrm{kg}$; ST 285 suşu ile $37^{\circ} \mathrm{C}$ 'de inkübe edilen yoğurtta ise $768 \mathrm{~g} / \mathrm{kg}$ EPS belirlenmiş ve depolama süresince EPS miktarında büyük ölçüde azalma gözlenmiştir [37]. 
Gürsoy ve arkadaşları [38] ticari başlatıcı kültürler ve yüksek EPS üretimine sahip yerli $L$. bulgaricus (B3) ve Str. thermophilus (W22) türlerini farklı oranlarda karıştırarak yoğurt üretiminde kullanmıştır. Üretilen yoğurtlar 21 gün buzdolabında depolanmış, 10 gün arayla fizikokimyasal testlere tabi tutulmuştur. Kontrol grubu ise sadece ticari başlatıcı kültür ile üretilmiştir. Yapılan analizler sonucu en yüksek asit içeriği kontrol grubunda tespit edilmiş sadece EPS üretimi yüksek suşlarla üretilen yoğurtta tirozin içeriği yüksek, EPS ve asetaldehit miktarı düşük çıkmıştır. Nehad ve El-Shamy [4] tarafından yapılan bir araştırmada ise çevresel şartların küflerin EPS üretimi üzerindeki etkileri araştırılmıştır. $\mathrm{Bu}$ amaçla EPS üretimi yüksek olan 6 adet Alternaria alternata türü kullanılmıştır. Optimum $30{ }^{\circ} \mathrm{C}$ sicaklıkta ve $\mathrm{pH} 3.0$ 'da en iyi karbon kaynağının \%4 glikoz olduğu ve en iyi azot kaynağının ise $\% 2$ maya ekstraktı olduğu belirtilmiştir.

\section{EPS'lerin Fizyolojik Özellikleri}

Ürünlere kazandırdığı teknolojik özelliklerin yanı sıra, yapılan çalışmalarla EPS'lerin bağışıklık sistemini geliştirici, kolesterolü düşürücü, antiülser, antitümör ve antimutajenik etki gibi sağlık üzerine olumlu etkileri olduğu bildirilmektedir [12, 39]. Serbest radikallerin yaşayan organizmaya verdiği hasarı önlemek amacıyla sentetik ve doğal antioksidanlar kullanılmaktadır. Sentetik antioksidanların karsinojenez ve karaciğer hasarına neden olduğu düşüncesi, insan sağlığını serbest radikallerden koruyacak doğal, toksik olmayan antioksidanların üretimini önemli kılmaktadır [19, 40].

EPS'lerin antioksidan ve serbest radikal bağlayıcısı olduğu kanıtlanmıştır. EPS'ler serbest radikalleri bağlayarak bitkisel yağların oksidasyonun önler. Kishk ve arkadaşları [41] tarafından yapılan çalışmada Rhizobium meliloti'den izole edilen EPS'lerin antioksidan ve şelat aktivitesi belirlenmeye çalışılmıştır. EPS ilave edilen bitkisel yağ emülsiyonunun $60^{\circ} \mathrm{C}$ 'de 5 saat boyunca güneş ışığına maruz bırakıldıktan sonra lipit oksidasyonunu inhibe ettiği rapor edilmiştir.

Başka bir çalışmada ise bifidobakteri, laktobasil ve streptokok suşları tarafından üretilen EPS'lerin antiülser etkiye sahip olduğu bildirilmiştir. Ancak EPS üreten LAB tarafından epitel dokunun korunma metabolizması detaylıca açıklanamamıştır [42]. EPS’ler sindirim sistemindeki bakteriler tarafından parçalanamadıkları için prebiyotik özellik göstermektedir. Başka bir araştırmada $L$. sanfranciscencis' in bir suşu tarafindan üretilen fruktan tipi bir EPS’nin prebiyotik bir substrat olabileceği ispat edilmiştir [43]. İntestinal bölgede bulunan bifidobakteri üyelerinin ürettiği EPS’nin, bağırsakta bulunan mikroorganizmalar arasında etkileşimi modifiye ettiği belirtilmiştir [44].

Rodríguez ve arkadaşları [45] tarafından yapılan bir çalışmada Str. thermophilus CRL 1190 suşundan saflaştırılan EPS'nin kronik gastrite karşı koruyucu etkisinin olduğu bildirilmiştir. Araştırıcılar EPS-protein etkileşiminin mide koruyucu etkiden sorumlu olabileceğini ifade etmişlerdir. Nakajima ve arkadaşları [46] tarafından yapılan çalışmada Lc. cremoris SBT 0495 tarafından üretilen EPS'lerin farelerde karın içi antikor üretimini arttırdığı belirtilirken, Kitazawa ve arkadaşları [47] tarafindan EPS üreticisi L. bulgaricus OLL1073R-1'in antitümör aktivitesine sahip olduğu kaydedilmiştir. Diğer taraftan kefir daneleri tarafından üretilen suda çözünür EPS'nin ağız yolu ile tüketiminin tümör gelişimini geciktirici etkisi olduğu belirlenmiştir [48]. Saccharomyces cerevisiae, Ganoderma applanatum ve Cordyceps sinensis gibi farklı türler tarafından üretilen polisakkaritlerin bulaşıcı hastalıkların tedavisinde etkili olabileceği düşünülmektedir. Fungal ve bakteriyel polisakkaritler bağışıklı sisteminin 
düzenlenmesinde anahtar görevi gördüğü belirtilmiştir [49]. Liu ve arkadaşlarının [19] yaptığı bir çalışmada Paenibacillus polymyxa EJS-3 suşundan sentezlenen EPS-1 ve EPS-2'nin molekül ağırlıkları sırasıyla 1220 ve 869 kDa olarak tespit edilmiştir. Diğer bir çalışmada ise, karbon kaynağı olarak glikoz kullanılmış ve P. polymyxa ATCC 21830 suşunun ürettiği EPS'nin ortalama moleküler ağırlı̆̆ $170 \mathrm{kDa}$ olarak tespit edilmiştir [18].

\section{EPS’lerin Teknolojik Özellikleri}

Son zamanlarda mikrobiyal EPS'ler ve türevleri doğal gamlar ve sentetik polimerlere göre farklı fizyolojik aktiviteye sahip olmaları nedeniyle gıda, ilaç ve diğer endüstriler olmak üzere birçok alanda kullanılmaktadır [50, 51]. EPS'ler gıda sanayisinde; viskoziteyi artırıcı, yapıyı düzenleyici, su bağlayıcı, stabilize ve emülsiye edici olarak kullanılmaktadır. Bu amaçla EPS üreten LAB güvenli EPS kaynağı olarak gıda sanayisinde kullanılmaktadır [52]. LAB tarafindan üretilen ve GRAS (genel olarak güvenli kabul edilen) statüsünde yer alan EPS'ler başta süt endüstrisinde olmak üzere, et ve sebze gibi çiğ gıda ürünlerinin fermantasyonunda endüstriyel ölçekte uygulanmaktadır [16, 53]. LAB'lar süt endüstrisinde kulanılan başlatıcı kültürlerin büyük bir kısmını oluşturmaktadır. Bu bakteriler süt endüstrisinde; süt şekerini parçalayarak laktik asidi meydana getirme, süt yağı ve proteinleri parçalayarak ürünün kendisine has tat, aroma ve yapısının meydana gelmesini sağlamaları nedeniyle tercih edilmektedirler [54]. Fakat günümüzde bu özelliklere sahip LAB'ların yanı sıra EPS üreten LAB'ların kullanımına büyük önem verilmektedir. Yapılan araştırmalarda EPS üreten LAB'lar genel olarak yapışkan (ropy) kültür olarak tanımlanırlar [55]. Yaklaşık olarak 30 EPS üreticisi LAB türü tanımlanmıştır. Bunlar arasında en çok bilinenleri L. casei, L. acidophilus, L. brevis, L. curvatus, L. bulgaricus, L. helveticus, L. rhamnosus, $L$. plantarum ve L. johnsonii'dir [56]. Fermente süt ürünleri ve yoğurt ürünlerinin üretiminde EPS, kıvamın ve tekstürün arzu edilen özellikte olması için gereklidir.

LAB tarafindan üretilen EPS'ler yoğurt ve diğer fermente süt ürünlerinin yapısını geliştirmek amacıyla yaygın olarak kullanılmaktadır [57]. EPS'ler süt sanayisinde; gıda katkı maddesinin kullanımını azaltmak, yoğurdun viskozitesini geliştirmek, yapıyı ve aromayı iyileştirmek, fermantasyon süresi boyunca ve depolama sırasında sinerezisi önlemek ayrıca tekstürün oluşmasında, lezzetin algılanmasında, ağızdaki hissi ve istenilen yapının oluşmasında temel rol oynar [24]. Kuzey ve Doğu Avrupa ile Asya yoğurtlarında EPS yaygın olarak kullanılmaktadır [58]. EPS sentezleyen suşlarla üretilen yoğurtların reolojik ve tekstürel özellikleri üzerine yapılan çok sayıda çalışma bulunmaktadır [11].

Yoğurt üretiminde özellikle yapının düzenlenmesi, viskozite ve su tutma kapasitesinin geliştirilmesi ve serum ayrılmasını azaltmak amacı ile EPS üreten Str. thermophilus ve L. bulgaricus suşları yaygın olarak kullanılmaktadır [59]. Yoğurttaki farklı başlatıcı kültürler tarafindan üretilen EPS aralığı 45-350 mg/L arasında olduğu rapor edilmiştir [12]. EPS yoğurdun duyusal özelliklerinin raf ömrü süresince korunabilmesi açısından önem arz etmektedir. Ticari kültürlerin EPS üretme potansiyeli ve yoğurdun viskozitesine olan etkisinin araştırıldığı bir çalışmada [60] 3 ticari başlatıcı kültürü 3 farklı ortama (MRS besiyeri, süt ve yoğurt) inoküle edip EPS miktarı tayin edilmiştir. Yoğurtta EPS miktarı $144.08 \mathrm{mg} / \mathrm{L}$ ile $440.81 \mathrm{mg} / \mathrm{L}$ arasında bulunmuştur.

Optimum koşullarda maksimum EPS üretimini sağlamak amacıyla yapılan başka bir çalışmada en iyi EPS verimi sağlayan ortamın bileşeni ve miktarını belirlemek amacıyla karbon, azot ve tuz kaynağı 
olarak sırayla glikoz, maya ekstraktı ve $\mathrm{MgSO}_{4}$ kullanılmıştır. Alcaligenes faecalis B14 suşu \%5 oranında inoküle edilmiş ve $30^{\circ} \mathrm{C}$ 'de 100 rpm'de inkübe edilmiştir. En yüksek EPS verimi glikoz, maya ekstraktı ve $\mathrm{MgSO}_{4}$ kullanıldığı besiyerinde tespit edilmiştir. Ayrıca EPS konsantrasyonunun artmasının viskozitenin artışına sebep olduğuda ifade edilmiştir [61].

Hassan ve arkadaşları tarafindan yapılan araştırmada [62] jelleştirici kültürlerle üretilen yoğurtların su salma oranlarında azalma gözlenmiştir. Ticari kültüre $(\% 1,5)$ ek olarak EPS üretimi tespit edilmiş L. bulgaricus B3 ve Str. thermophilus W22 suşları ile üretilen yoğurtlarda daha yüksek EPS üretimi belirlenmiştir. Viskozite değerleri açısından da bu suşların kullanıldığı yoğurtların daha kıvamlı olduğu belirtilmiş̧ir. Yapılan başka bir çalı̧̧mada ise polisakkarit üreten kültürlerin kullanımı ile yoğurdun viskozitesinin önemli ölçüde arttığı belirlenmiş ve mukoz yapıda EPS üreten suşlarla yapılan yoğurtların EPS sentezine sahip olmayan kültürlerle yapılarına göre viskozitelerinin daha yüksek olduğu tespit edilmiştir [63].

Broadbent ve arkadaşları [64] Str. thermophilus ST 285 ve ST 1275 suşlarını kullanarak, farklı sıcaklıklarda ürettikleri set tipi yoğurtların depolama süresi boyunca teknolojik ve reolojik özelliklerini incelemişlerdir. Yapılan çalışmada ST 1275 suşu ile üretilen yoğurtların asitliğinin daha hızlı geliştiği, bu yoğurtların düşük sinerezis ve yüksek akış indeksine sahip olduğu belirtilmiştir. Mükemmel bir su tutma kapasitesine sahip olan EPS'ler bu özellikleri ile özellikle düşük yağlı peynirlerin fonksiyonel özelliklerini geliştirmek amacı ile peynir teknolojisinde de geniş bir kullanım alanına sahiptir. Düşük yağlı peynirlerin sert ve lastiğimsi yapıya sahip olmaları ve erimeleri için daha fazla ısıya ihtiyaç duymaları önemli bir dezavantajdır. Bu nedenle erimenin zor gerçekleştiği, düşük yağ oranına sahip peynirlerde yüksek su tutma kapasitesine sahip EPS'lerin kullanımına yönelik çeşitli çalışmalar yapılmıştır. L. bulgaricus MR-1R ve Str. thermophilus MR-1C suşları tarafindan sentezlenen EPS'lerin su bağlama özelliklerinin araştırıldığı bir çalışma sonucunda Str. thermophilus MR-1C suşu tarafından üretilen kapsüler EPS'nin peynirin su seviyesini önemli miktarda artırdığı tespit edilmiş̧ir [65].

EPS'ler yoğurt ve peynirin yanı sıra kefir, ekşi krema gibi diğer bazı fermente süt ürünlerinin de reolojik özelliklerini etkilemektedir [66]. EPS üreten LAB'ların kullanımı sadece fermente süt ürünleri üretimi ile sınırlı değildir. Örneğin Leu. mesenteroides tarafından üretilen dekstran firıncılık katkı maddesi olarak kullanım alanı bulmaktadır [24]. Hamura yeterli miktarda EPS ilavesi ile glutenin yumuşayarak tekstürün gelişmesi, raf ömrünün uzaması ve son üründe hacim artışı meydana gelmektedir [67]. Branth ve arkadaşları [68] tarafından yapılan bir çalışmada EPS'lerin ekmek kalitesini ve hamurun reolojik parametrelerini geliştirdiği bildirilmiştir. Laktobasillerden üretilen polimerlerin; hamurun su absorpsiyonu, hamur reolojosi ve işlenebilirliğini, ekmek hacmi ve ekmeğin bayatlamaması gibi hamurun ve ekmeğin teknolojik özelliklerini olumlu etkiyebileceği ifade edilmiştir [24].

Doğan ve arkadaşlarının [69] yaptı̆̆ı bir çalışmada farklı yağ seviyeleri (\% 25-100) ve EPS içeren çözeltinin farklı seviyeleri (\% 9.25-37) kullanılarak yağ oranı azaltılmış kek üretilmiştir. Üretilen keklerin sertlik, yapışkanlık ve esneklik değerlerinin yağ ve EPS interaksiyonundan önemli seviyede etkilendiği, tüm kek özellikleri göz önüne alındığında yağ ve EPS oranının artmasıyla beğenilirlik değerinin arttığı gözlenmiştir. 
6. Sonuç

EPS'ler viskoziteyi arttırıcı, yapıyı düzenleyici ve su bağlayıcı gibi fonksiyonel özelliklerinden dolayı süt ürünlerinde ticari stabilizatörlerin yerine alternatif olarak kullanılabilmektedir. Oldukça düşük konsantrasyonlarda üretilen ekzopolisakkaritin bile yapıyı geliştirici etkisi olduğu belirlenmiştir. Bu nedenle bazı fermente süt ürünlerinin üretiminde ekzopolisakkarit üreten bakterilerin kullanılmasına önem verilmektedir. Böylece hiçbir katkı maddesi kullanılmadan son ürünün tekstürel özelliğini arzu edilen şekilde geliştirerek tüketicilerin ihtiyaç ve taleplerini karşılamak mümkün olabilmektedir. Gıdalarda reolojik özelliklerinin geliştirmesine yanı sıra EPS üreten LAB konakçı üzerine daha iyi tutunabilmektedir. EPS üreten mikroorganizmaların gıda endüstrisinde kullanımına yönelik çalışmaların sayısı giderek artmaktadır, bu artışın raflarda daha kaliteli gıdaların yerini almasına sebep olacağı düşünülmektedir.

\section{Kaynaklar}

[1] Freitas F., Alves V.D., Reis M.A., “Advances in bacterial exopolysaccharides: from production to Biotechnological applications” Trends in Biotechnology, 29, 388-398, 2011

[2] Becker A., Katzen F., Pühler A., Ielpi L., "Xanthan gum biosynthesis and application: a biochemical/genetic Perspective” Applied Microbiology and Biotechnology, 50, 145-152, 1998

[3] Iyer ,A., Mody, K., Jha B., "Characterization of an exopolysaccharide produced by a marina Enterobacter cloacae” Indian Journal of Experimental Biology, 43(5), 467-71, 2005

[4] Nehad E. A., El-Shamy A.R., "Physiological studies on the production of exopolysaccharide by Fungi” Agriculture and Biology Journal of North America, 1, 1303-8, 2010

[5] Nwodo U. U., Green E., Okoh A. I., "Bacterial exopolysaccharides: functionality and prospects" International Journal of Molecular Sciences, 13(11), 14002-14015, 2012

[6] Nicolaus B., Manca M. C., Romano I., Lama L., "Production of an exopolysaccharide from two thermophilic archaea belonging to the genus Sulfolobus” FEMS Microbiology Letters, vol. 109, 2-3, 203-206, 1993

[7] Hartzell P. L., Millstein J., Lapaglia C., "Biofilm formation in hyperthermophilic archaea” Methods in Enzymology, vol. 310,335-349, 1999

[8] Duboc P., Mollet B., “Applications of exopolysaccharides in the dairy industry” International Dairy Journal ,11, 759- 768, 2001

[9] Liang T. W., Wang S.L., "Recent advances in exoplysaccharides from Paenibacillus spp. : Production, isolation, structure, and bioactivities” Marine Drugs, 13, 1847-1863, 2015

[10] Vaningelgem F., Zamfir M., Mozzi F., Adriany T., Vancanneyt M., Swings J., De Vuyst L., "Biodiversity of Exopolysaccharides Produced by Streptococcus thermophilus Strains is Reflected in their Production and their Molecular and Functional Characteristics” Applied and Environmental Microbiology, 70 (2), 900-912, 2004 
[11] Ruas-Madiedo P., Hugenholtz J., Zoon P., "An overview of the functionality of exopolysaccharides produced by lactic acid bacteria” International Dairy Journal, 12, 163-171, $2002 a$

[12] De Vuyst L., Degeest B., “Heteropolysaccharides from lactic acid bacteria” FEMS Microbiology Reviews, 23, 153-177, 1999

[13] Poli A., Di Donato P., Abbamondi G. R., Nicolaus B., "Synthesis, production, and biotechnological applications of exopolysaccharides and polyhydroxyalkanoates by archaea” Hindawi Publishing Corporation Archaea, Article ID 693253, 13 pages doi:10.1155/2011/693253, 2011

[14] Cerning J., "Production of exopolysaccharides by lactic acid bacteria and dairy propionibacteria” Le Lait, 75(4-5), 463-472, 1995

[15] Nicolaus B., Kambourova M., Oner E.T., "Exopolysaccharides from extremophiles: from fundamentals to biotechnology” Environmental Technology, 31,10, 1145- 1158, 2010

[16] Welman A.D., Maddox S., "Exopolysaccharides from lactic acid bacteria: perspectives and challenges” Trends in Biotechnology, 21, 269-274, 2003

[17] Grosu-Tudor S.S., Zamfir M., "Exopolysaccharide production by selected lactic acid bacteria isolated from fermented vegetables” Scientific Bulletin Series F. Biotechnologies, 18, 22851364, 2014

[18] Rafigh S.M., Yazdi A.V., Vossoughi M., Safekordi A.A., Ardjmand M., "Optimization of culture medium and modeling of curdlan production from Paenibacillus polymyxa by RSM and ANN” International Journal of Biological Macromolecules, 70, 463-473, 2014

[19] Liu J., Luo J., Ye H., Sun Y., Lu Z., Zeng X., "Production, characterization and antioxidant activities in vitro of exopolysaccharides from endophytic bacterium Paenibacillus polymyxa EJS-3” Carbohydrate Polymers, 78, 275-281, 2009

[20] Liu J., Luo J., Ye H., Sun Y., Lu Z., Zeng X., “ Medium optimization and structural characterization of exopolysaccharides from endophytic bacterium Paenibacillus polymyxa EJS3” Carbohydrate Polymers, 79, 206-213, 2010

[21] Rehm, B.H.A. (ed.) Microbial production of biopolymers and polymer precursors: applications and perspectives, Caister Academic Press, (2009)

[22] Mozzi F., Oliver G., De Giori G.S., De Valdez G.F., "Influence of temperature on the production of exoplysaccahiredes by thermophilic lactic acid bacteria” Milchwissenschaft Journal, 50 (2), 80-82, 1995

[23] Yang Z., Li S., Zhang X., Zeng X., Li D., “Capsular and slimepolysaccharide production by Lactobacillus rhamnosus JAAS8 isolated from Chinese sauerkraut: Potential application in fermented milk products” Journal of Bioscience and Bioengineering, 110, 53-57, 2010

[24] Patel A., Prajapati J.B., "Food and Health Applications of Exopolysaccharides produced by Lactic acid Bacteria” Advances in Dairy Research 1:107. doi: 10.4172/2329-888X.1000107, 2013 
[25] Grosu-Tudor S., Zamfir M., "Functional properties of lactic acid bacteria isolated from Romanian fermented vegetables” Food Biotechnology, 27 (3), 235-248, 2013

[26] Jolly L., Vincent S.J., Dubic P., Neeser J.R., "Exploiting exopolysaccharides from lactic acid bacteria” Antoine van Leevuwenhoek, 84, 367-374, 2002

[27] Cerning J., Bouillanne M., Desmazeaud M., Landon M., "Exocellular polysaccharide production by Streptococcus thermophilus” Biotechnology Letters, 10, 255- 260, 1988

[28] Doco T., Fournet B., Carcano D., Ramos P., Loones A., “ Structure of an exocellular polysaccharide produced by Streptococcus thermophilus” Carbohydrate Research, 198, 313321, 1990

[29] Garcia-Garibay M., Marshall V. M. E., "Polymer production by Lactobacillus delbrueckii ssp bulgaricus” Journal of Applied Bacteriology, 70, 325-328, 1991

[30] Cerning J., Bouillanne C., Landon M., Desmazeaud M., "Isolation and characterization of exopolysaccharides from slime-forming mesophilic lactic acid bacteria” Journal of Dairy Science, 75, 692-699, 1992

[31] Patel A., Prajapati J. B., Holst O., Ljungh A., "Determining probiotic potential of exopolysaccharide producing lactic acid bacteria isolated from vegetables and traditional Indian fermented food products” Food Bioscience, 5, 27-33, 2014

[32] Van Geel-Schutten G. H., Flesch F., Ten Brink B., Smith M. R., Dijkhuizen L., "Screening and characterization of Lactobacillus strains producing large amounts of exopolysaccharides" Applied Microbiology and Biotechnology, 50(6), 697-703, 1998

[33] Faber E.J., Zoon P., Kamerling J.P., Vliegenthart J.F.G., “The exopolysaccharides produced by Streptococcus thermophilus Rs and Sts have the same repeating unit but differ in viscosity of their milk cultures” Carbohydrate Research, 310, 269-276, 1998

[34] Shihata A., Shah N. P., "Influence of addition of proteolytic strains of Lactobacillus delbrueckii subsp bulgaricus to commercial ABT starter cultures on texture of yoghurt, exopolysaccharide production and survival of bacteria” International Dairy Journal, 12(9), 765-772, 2002

[35] Lin T. Y., Chang Chien M. F., "Exopolysaccharides production as affected by lactic acid bacteria and fermentation time” Food Chemistry, 100, 1419-1423, 2007

[36] Prasanna P. H. P., Grandison A.S., Charalampopoulos D., "Screening human intestinal Bifidobacterium strains for growth, acidification, EPS production and viscosity potential in lowfat milk” International Dairy Journal, 23(1), 36-44, 2012

[37] Purwandari U., Shah N. P., Vasiljevic T., "Effects of exopolysaccharide-producing strains of Streptococcus thermophilus on technological and rheological properties of set-type yoghurt" International Dairy Journal, 17(11), 1344-1352, 2007

[38] Gürsoy A., Durlu-Özkaya F., Yildiz F., Aslim B., "Set type yoghurt production by exopolysaccharide producing Turkish origin domestic strains of Streptococcus thermophilus (W22) and Lactobacillus delbrueckii ssp. bulgaricus (B3) "Kafkas Universitesi Veteriner Fakültesi Dergisi, 16, 81-86, 2010 
[39] Tsuda H., Hara K., Miyamoto T., "Binding of mutagens to exopolysaccharide produced by Lactobacillus plantarum mutant strain 301102S” Journal of Dairy Science, 91, 2960-2966, 2008

[40] Mahapatra S., Banerjee D., "Evaluation of in vitro antioxidant potency of exopolysaccharide from endophytic Fusarium solani SD5” International Journal of Biological Macromolecules, 53, 62-66, 2013

[41] Kishk Y.F.M., Al-Sayed H.M.A., “ Free-radical scavenging and antioxidative activities of some polysaccharides in Emulsions” LWT- Food Science and Technology, 40: 270-277, 2007

[42] Nagaoka M., Hashimoto S., Watanabe T., Yokokura T., Moro Y., "Anti-ulcer effects of lactic acid bacteria and their cell wall polysaccharides” Biological and Pharmaceutical Bulletin, 17, 1012-1017, 1994

[43] Korakli M., Gänzle M.G., Vogel R.F., "Metabolism by bifidobacteria and lactic acid bacteria of polysaccharides from wheat and rye, and exopolysaccharides produced by LactoBacillus sanfranciscensis” Journal of Applied Microbiology, 92, 958-965, 2002

[44] Salazar N., Gueimonde M., Hernandez-Barranco A.M., Ruas-Madiedo P., de los Reyes-Gavilan C.G ., "Exopolysaccharides produced by intestinal Bifidobacterium strains act as fermentable substrates for human İntestinal bacteria” Applied and Environmental Microbiology, 74, 47374745, 2008

[45] Rodríguez C., Medici M., Rodríguez A.V., Mozzi F., Font de Valdez G., "Prevention of chronic gastritis by fermented milks made with exopolysaccharideproducing Streptococcus thermophilus strains” Journal of Dairy Science, 92, 2423- 2434, 2008

[46] Nakajima, H., Toba, T., Toyoda, S., "Enhancement of antigenspecific antibody production by extracellular slime products from slime-forming Lactococcus lactis subsp. cremoris SBT 0495 in mice” International Journal of Food Microbiology, 25, 153-158, 1995

[47] Kitazawa, H., Harata, T., Uemura, J., Daito, T., Kaneko, T., Itoh, T., "Phosphate group requirement fo mitogenic activation of lymphocytes by an extracellular phosphopolysaccharide from Lactobacillus delbrueckii spp. bulgaricus” International Journal of Food Microbiology, 40, 169-175, 1998

[48] Zubillaga M., Weill R., Postaire E., Goldman, C., Caro R., Boccio J., "Effect of probiotics and functional foods and their use in different diseases” Nutrition Research, 21, 569-579, 2001

[49] Schepetkin I.A., Xie G., Kirpotina L.N., Klein R.A., Jutila M.A., Quinn M.T., “Macrophage immunomodulatory activity of polysaccharides isolated from Opuntia polyacantha” International Immunopharmacology, 8, 1455-1466, 2008

[50] Kumar A.S., Mody K., Jha B., "Bacterial exopolysaccharides-A perception” Journal of Basic Microbiology, 47, 103-117, 2007

[51] Freitas, F.; Alves, V.D.; Pais, J.; Costa, N.; Oliveira, C.; Mafra, L.; Hilliou, L.; Oliveir, R.; Reis, M.A.M., "Characterization of an extracellular polysaccharide produced by a Pseudomonas strain grown on glycerol” Bioresource Technology, 100, 859-865, 2009

[52] Frengova GI., Simova ED., Beshkova DM., Simov ZI., "Exopolysaccharides produced by lactic acid bacteria of kefir grains” Verlag der Zeitschrift für Naturforschung, 57, 805-810, 2002 
[53] Kleerebezem M., Hugenholtz J., "Metabolic pathway engineering in lactic acid bacteria" Current Opinion in Biotechnology, 14, 232-237, 2003

[54] Yaygın H., K1lıç S., Süt Endüstrisinde Saf Kültür. Alttndăg Matbaacıllk,107s, İzmir, 1993

[55] Laws PA., Marshall M.V., "The Revelance ofExopolysaccharides to the Rhelogical Properties in Milk Fermented with Ropy Strains of Lactic Acid Bacteria” International Dairy Journal, 709721, 2001

[56] Tabibloghmany FS., Ehsandoost E., "An Overview of Healthy and Functionality of Exopolysaccharides Produced by Lactic Acid Bacteria in the Dairy Industry” European Journal of Nutrition \& Food Safety, 4, 63-86, 2014

[57] Faber E.J., Kamerling J.P., Vliegenthart J.F., "Structure of the extracellular polysaccharide produced by LactoBacillus delbrueckii subsp. bulgaricus 291" Carbohydrate Research, 331, 183-194, 2001

[58] Kodali V. P., Das S., Sen R., "An exopolysaccharide from a probiotic: Biosynthesis dynamics, composition and emulsifying activity” Food Research International, 42(5), 695-699, 2009

[59] Ruas-Madiedo P., Tuinier R., Kanning M., Zoon P., "Role of exopolysaccharides produced by Lactococcus lactis subsp. cremoris on the viscosity of fermented milks" International Dairy Journal, 12 ,689-685, 2002b

[60] Feldmane, J., Semjonovs, P., Ciprovica, I., "Potential of exopolysaccharides in yoghurt production" In Proceedings of World Academy of Science, Engineering and Technology, 80, p. 299, 2013

[61] Kaur V., Bera M.B., Panesar P.S., Chopra H.K., "Production and Characterization of Exopolysaccharide Produced by Alcaligenes Faecalis B14 Isolated from Indigenous Soil" International Journal of Biotechnology and Bioengineering Research, 4, 365-374, 2013

[62] Hassan A.N., Frank J.F., Schmidt K..A., Shalabi, S.I., "Textural properties of yogurt made with encapsulated nonropy lactic cultures” Journal Dairy Science, 79, 2098-2103. 1996

[63] Hassan AN., Corredig M Frank J.F., "Viscoelastic properties of yogurt made with ropy and nonropy exopolysaccarides producing cultures” Milchwissenschaft Journal, 56(12), 684-687, 2001

[64] Broadbent JR., McMahon DJ., Oberg C.J., Welker DL., "Use of exopolysaccharide-producing cultures to improve the functionaltiy of low fat cheese" International Dairy Journal,11, 433439, 2001

[65] Low D., Ahlgren J.A., Horne D., McMahon D.J., Oberg C.J., Broadbent J.R., “ Role of Streptococcus thermophilus MR-1C capsular exopolysaccharide in cheese moisture retention" Applied and Environmental Microbiology, 64, 2147-2151, 1988

[66] Obert G., "Manufacturing of technology of cream turo with extended shelf life \& isolation of a special strain of lactic acid bacteria which improves product consistency (in Hungarian)" Teijipar 33, 47-48, 1984

[67] Madhuri K. V., Prabhakar K. V., "Microbial Exopolysaccharides: Biosynthesis and Potential" Applications. Oriental Journal of Chemistry, 30(3), 1401-1410, 2014 
Soyuçok A., Ekiz T., Başyiğit Kılıç G.

[68] Brandt M., Roth J.K., Hammes W.P., Effect of an exopolysaccharide produced by Lactobacillus sanfranciscensis LTH1729 on dough and bread quality. In: L de Vuyst Sourdough from fundamentals to applications (p 80) Brussels: Vrije Universiteit Brussel, 2003

[69] Doğan İ.S., Akbaş Ö., Tunçtürk Y., "Yağı azaltılmış kek üretiminde ekzopolisakkarit kullanımı" Gıda, 37(3), 141- 148, 2012 